\title{
Is the TEF a good idea - and will it work?
}

Nick Hillman

This reflection piece is based on a lecture delivered at Greenwich in November 2016.

The Teaching Excellence Framework (TEF) is designed to evaluate the quality of teaching and learning in higher education and to reward or punish institutions accordingly. The idea of some sort of Teaching Excellence Framework is older than many people realise. It was floating around Whitehall before I left my role as special adviser to the Minister for Universities and Science in late 2013. At that time, we were vaguely thinking of a TREF: a Teaching and Research Excellence Framework that would be light touch and perhaps piggyback on the REF. But, in truth, our thinking had not gone very far.

There were three progenitors of the idea.

First, my then boss, David Willetts, was worried that measures of institutional performance flattered ancient research-intensive institutions but did the opposite for institutions focusing on great teaching. If those that focus on excellent research are applauded for it, it is surely only fair that those that focus on excellent teaching receive similar plaudits.

Second, when $£ 9,000$ tuition fees came in, ministers said universities would be much more responsive to their students. My job entails visiting around fifty higher education institutions each year and, as I travel around, I see that this has happened. But ministers lack hard supportive data and thus have been unable to prove unequivocally that teaching and learning have improved as a result of their reforms.

Third, we have to accept that not all students are as engaged as they should be. For example, our annual Student Academic Experience Survey, undertaken with the Higher Education Academy, shows that, on average, they work for only three-quarters of the time that the Quality Assurance Agency say they should.

So, I understand where the Government is coming from on the TEF, but I do worry about the statistical proxies by which university teaching is to be measured. I also worry about its implementation and structure. That explains why the Higher Education Policy Institute has 


\section{TEF Special Edition}

published more detailed critiques of the TEF than anyone else, including, as well as various blogs on specific aspects, four lengthy papers:

1. In early 2016, we published Professor Graham Gibbs's critique of the higher education green paper. He argued for the TEF to be replaced with process measures focusing on student engagement: 'The Government must choose between obliging universities to give students what they say they want, even if it is counter-educational, and encouraging forms of provision which are known to be more educationally effective, whether students want them or not.'

2. We published a lecture by Andreas Schleicher, who is the OECD's Director of Education. He believes we should test students on what they know instead of using proxies. Only then would it be possible to compare the quality of, say, a Japanese Engineering student to a UK one. He argues we are much closer to being able to do this well than we were a few years ago and so the time has come to start measuring learning gain directly. That is a controversial proposal and difficult to do in practice, but measuring learning gain does have increasing appeal and HEFCE is now funding its own pilots on the idea.

3. We also published a paper by Louisa Darian that looks at whether there are lessons for the TEF from other sectors in receipt of public funding. She found some clear ones. For example, experience in healthcare shows that stability in the organisation delivering quality ratings is crucial to their success. Thought needs to be given to this, because the TEF is to be implemented alongside the abolition of the Higher Education for England and the establishment of the new Office for Students.

4. In autumn 2016, we published a polemical paper by Professor Paul Blackmore of King's College London, which argues that prestige comes from research and so the best way to put a new focus on teaching is to bring teaching and research closer together rather than to drive them apart. His paper argues that, because the TEF does nothing to integrate teaching with research, it could end up a sideshow to the REF. Instead, he called for more links between teaching and research at every level.

Despite the power of these critiques, it is important to be fair to the Government. For the TEF to happen quickly, you do need to use existing metrics rather than wait for better measures of teaching and learning to come along. We could wait for the data to be perfect but, if we do so, 


\section{TEF Special Edition}

the chances are the TEF would never actually happen. Jo Johnson makes a valid point when he cautions against comparing the first iteration of the TEF to the latest REF.

Moreover, ministers have proved admirably flexible on the way the TEF will operate. For example, the original timetable has been extended, universities are able to submit qualitative information to be assessed alongside their hard data and the TEF is, in due course, to shift to the basis of disciplines. Numerous tweaks have been made to the details as well.

It is a very different beast (in many ways, better) from the one Jo Johnson originally announced, even if it is bigger, bossier and more bureaucratic. We can still query the details - some people particularly dislike the Gold / Silver / Bronze hierarchy, which probably derives from the fact that 2016 was an Olympic year - but I do not think we can question the willingness of ministers or civil servants to alter their plans in response to valid concerns. My only hope is that they continue to be just as flexible in future as we learn from the process of rolling the TEF out.

There has been talk of a boycott of the TEF, particularly by older universities. I am sceptical that this will happen in any big way, because not all the sector is united against the TEF, universities want the fee increases that will come with success in the TEF and precedents suggest that those who stay out of sector-wide initiatives do not stay out for long. Perhaps, if the whole sector fiercely opposed the TEF and refused to play ball, they could kill it, but that is a battle that would have little public support at the very time when, post EU referendum, our universities are trying to show they are in close touch with the wider community.

I am also sceptical that the attempt by the National Union of Students to boycott the National Student Survey will have much impact. Even many student unions question whether it is the right approach and I do not see what incentive there is for students to hurt the reputation of their own universities in this way.

Overall, I think it is a good idea to respond to concerns about the quality of higher education by trying to assess the quality of teaching and learning. I think it is right to re-balance the incentives within universities to the benefit of teaching and learning. I also think the TEF results could prove useful to parents, teachers, advisers, applicants, students, graduates, staff and employers. Moreover, I believe none of us working in higher education should ever shy away from new information, however difficult. We should play with it, contextualise it, highlight its limits... and also learn from it. 


\section{TEF Special Edition}

However, I am uncomfortable about the link to fees, especially while the TEF is undertaken institutionally rather than at the level of disciplines: that seems to me to mix up ends and means and to focus debate on funding when it should be on pedagogy. I also worry that the TEF could hinder innovation in the classroom by encouraging safe rather than risky teaching. It would, for example, be a tragedy if the TEF meant difficult subjects were no longer taught or if it were to encourage spoon feeding at the expense of teaching designed to stretch students, develop their independent learning skills or help them to learn in research-like ways. So, most importantly, we must all be discriminating enough to select from the rollout of the new assessment of teaching and learning what helps rather than hinders.

The TEF has encouraged lots of technocratic discussions about teaching and learning. As a former teacher, I want to end by noting something else. There is no feeling in life as rewarding as successfully imparting knowledge to others. It is therefore incumbent upon us all to ensure that the TEF does not erect a new barrier between the teachers and the taught. 